\title{
Erratum to: Purification and characterization of a nitrilase from Aspergillus niger K10
}

\author{
Ondřej Kaplan • Vojtěch Vejvoda • Ondřej Plíhal • \\ Petr Pompach • Daniel Kavan • Pavla Bojarová • \\ Karel Bezouška • Martina Macková • Maria Cantarella • \\ Vladimír Jirků • Vladimír Křen • Ludmila Martínková
}

Published online: 3 March 2013

(C) Springer-Verlag Berlin Heidelberg 2013

\section{Erratum to: Appl Microbiol Biotechnol (2006) 73:567-575 DOI 10.1007/s00253-006-0503-6}

The previous article reported on the biochemical characterization of a nitrilase purified from Aspergillus niger K10. The amino acid sequence of this enzyme was recently analyzed by mass spectroscopy which revealed that the $\mathrm{N}$-terminal sequence reported in Fig. 3A (by KB) in the previous article was incorrect. This N-terminal sequence (XAPVLKKYKAAXVNXE),

Electronic supplementary material The online version of this article (doi:10.1007/s00253-013-4743-y) contains supplementary material, which is available to authorized users.

The online version of the original article can be found at http:// dx.doi.org/10.1007/s00253-006-0503-6.

O. Kaplan · V. Vejvoda $\cdot$ P. Bojarová · V. Křen •

L. Martínková $(\bowtie)$

Institute of Microbiology, Centre of Biocatalysis

and Biotransformation, Academy of Sciences

of the Czech Republic, Vídeňská 1083,

14220 Prague, Czech Republic

e-mail: martinko@biomed.cas.cz

O. Plíhal · P. Pompach • D. Kavan · K. Bezouška

Department of Biochemistry, Faculty of Science,

Charles University Prague, Hlavova 8,

12840 Prague, Czech Republic

M. Macková • V. Jirků

Faculty of Food and Biochemical Technology, Institute of Chemical Technology Prague, Technická 5,

16628 Prague, Czech Republic

\section{Cantarella}

Department of Chemistry, Chemical Engineering and Materials, University of L'Aquila, Monteluco di Roio,

67040 L'Aquila, Italy which was highly homologous to those of a number of hypothetical proteins in genus Aspergillus (Aspergillus fumigatus Af29, Aspergillus oryzae, Aspergillus nidulans FGSC A4) did not belong to the enzyme purified and characterized in the previous article. Mass spectrum analyses of this enzyme were recently performed as follows. Briefly, the peptides were extracted after in gel digestion of the enzyme with trypsin and analyzed by MALDI-ToF MS using Bruker Biflex IV (Bruker Daltonics, Germany). Alternatively, the peptides were analyzed by using UHPLC Dionex Ultimate3000 RSLC nano (Dionex, Germany) equipped with a ESI-Q-ToF Maxis Impact (Bruker Daltonics, Germany) mass spectrometer. Spectra were interpreted using Mascot software (Matrix Science, UK). These analyses (Fig. S1) suggested a 42.5-58.1\% sequence coverage of the enzyme with a putative nitrilase from Aspergillus kawachii IFO 4308 (gi|358373570) having N-terminal sequence MSHDGPKTIRVAAVQA (Fig. 1).

The N-terminal amino acid sequence reported in the previous article belonged to another enzyme encoded in the same strain $(\mathrm{gb} \mid \mathrm{ABX} 75546)$. This enzyme was later expressed in E. coli, purified and characterized, and its substrate specificity was found to be different from that of the nitrilase purified in A. niger K10 (Kaplan et al. 2011). This was hypothesized to be caused by a misfolding or by a posttranslational modification (Kaplan et al. 2011) but this hypothesis has been corrected according to the new MS analyses (Kaplan et al., Corrigendum to: Heterologous expression, purification and characterization of nitrilase from Aspergillus niger K10 (BMC Biotechnol (2011) 11:2). BMC Biotechnol, submitted manuscript). The aforementioned enzyme from A. nidulans FGSC A4 was later characterized as a cyanide hydratase (Basile et al. 2008). In 
1 MSHDGPKTIR VAAVOAEPEW NNLOKGVEKT IRLIIEAGKN GANVMGFPEV 51 WIPGYPWSIW NOSVVDNVEF MDEYFRNSLE RDSEEMNRIR CAVKEAGIFC 101 VLGYSERYQG SLYISQSFID ENGDIVHHRR KIKPTHVERG FWGEGQADSL 151 KSVVKSSFGN IGGLNCWEHT QTLLRYYEYA QNVDIHIASW PLIFGACAEM 201 QYHISSEMCG KLTQVMSMEG ACFTLICSQV MSAENCERNK VDKWSFVKAP 251 GGGFSMIYGP AGEPLVEAPD AGEEVILYAD VKLAEKWRAK QNLDVVGHYS 301 RPDLLSLKVT NNAASQVHFA

Fig. 1 Amino acid sequence of a hypothetical nitrilase from Aspergillus kawachii IFO 4308 (gi|358373570). The peptides identified in the purified nitrilase from Aspergillus niger K10 are marked in bold

accordance with this finding, the same activity was found in the protein $\mathrm{gb} \mid \mathrm{ABX} 75546$ expressed in E. coli. A detailed investigation of this activity is in progress.

Acknowledgement The authors acknowledge the MS spectra measurement and analysis carried out by Dr. J. Šantrůček (Institute of Chemical Technology in Prague, Czech Republic) and by Dr. P. Novák (Institute of Microbiology of the AS CR, Prague, Czech Republic).

\section{References}

Basile LJ, Willson RC, Sewell BT, Benedik MJ (2008) Genome mining of cyanide degrading nitrilases from filamentous fungi. Appl Microbiol Biotechnol 80:427-435

Kaplan O, Bezouška K, Plíhal O, Ettrich R, Kulik N, Vaněk O, Kavan D, Benada O, Malandra A, Šveda O, Veselá AB, Rinágelová A, Slámová K, Cantarella M, Felsberg J, Dušková J, Dohnálek J, Kotik M, Křen V, Martínková L (2011) Heterologous expression, purification and characterization of nitrilase from Aspergillus niger K10. BMC Biotechnol 11:2 